\title{
Lymphedema following cancer therapy in Slovenia: a frequently overlooked condition?
}

\author{
Tanja Planinsek Rucigaj, Nada Kecelj Leskovec, Vesna Tlaker Zunter
}

Department of Dermatovenereology, University Medical Center Ljubljana, Ljubljana, Slovenia

Received 4 October 2010

Accepted 20 October 2010

Correspondence to: Tanja Planinšek Ručigaj, M.D., Department of Dermatovenereology, University Medical Center Ljubljana, Zaloška 2, 1525 Ljubljana, Slovenia; Phone:+386 1522 4280; Fax:+386 1522 4333; E-mail: t.rucigaj@gmail.com

Disclosure: No potential conflicts of interest were disclosed

Introduction. Secondary lymphedema following cancer therapy is a frequent, often painful, quality of life disturbing condition, reducing the patients' mobility and predisposing them to complications, e.g. infections and malignancies. The critical aspect of lymphedema therapy is to start as soon as possible to prevent the irreversible tissue damage. Patients and methods. We performed a retrospective study of patients with lymphedema, treated at the Department of Dermatovenereology, University Medical Center Ljubljana, from January 2002 to June 2010. The patients' demographic and medical data were collected, including type of cancer, type and stage of lymphedema, and time to first therapy of lymphedema. The number of referred patients with lymphedema following the therapy of melanoma, breast cancer, and uterine/cervical cancer, was compared to the number of patients expected to experience lymphedema following cancer therapy, calculated from the incidence reported in the literature.

Results. In the period of 8.5 years, 543 patients (432 females, 112 males) with lymphedema were treated. The results show that probably many Slovenian patients with secondary lymphedema following cancer therapy remain unrecognized and untreated or undertreated. In the majority of our patients, the management of lymphedema was delayed; on average, the patients first received therapy for lymphedema 3.6 years after the first signs of lymphedema.

Conclusions. To avoid a delay in diagnosis and therapy, and the complications of lymphedema following cancer therapy, the physician should actively look for signs or symptoms of lymphedema during the follow-up period, and promptly manage or refer the patients developing problems.

Key words: Iymphedema, secondary lymphedema; cancer therapy, adverse effects; radiotherapy, adverse effects

\section{Introduction}

Lymphedema is swelling due to excess accumulation of lymph in the tissues caused by inadequate lymph drainage. Lymphedema differs clinically form other forms of chronic edema by its altered skin texture and brawny quality of the subcutaneous tissues which limit pitting. Primary lymphedema implies a genetic or constitutive cause whereby there is an intrinsic fault in the lymph drainage determined by the lymphatic maldevelopment or functional weakness. Secondary lymphedema implies an acquired failure of previously normal lymph drainage due to an identifiable cause extrinsic to the lymphatic system. ${ }^{1}$ Secondary types of lymphedema are more common than the prima- ry ones. In developed countries, cancer treatment dominates as a cause, whereas in tropical climates lymphedema is usually due to infections. ${ }^{2}$

The reports on worldwide incidence of lymphedema following cancer therapy in the available literature are scarce and varying considerably. The estimated incidence of breast cancer-related lymphedema is ranging from $13-50 \% .^{3-5}$ The introduction of sentinel lymph node biopsy reduced the incidence of lymphedema, however not as dramatically as it was hoped. ${ }^{1}$ The incidence of lower limb lymphedema following radical hysterectomy alone is estimated at $5-10 \%$ but can be as high as $49 \%$ by 10 years of follow-up in patients who also received the adjuvant radiation treatment. ${ }^{6-7}$ The incidence of lymphedema after lymphadenectomy 
TABLE 1. Staging of lymphedema

\begin{tabular}{lll}
\hline Stage & Clinical findings & Stemmer's sign \\
\hline 0 & Latent phase - no edema & Negative \\
I & Soft edema & Negative \\
II & $\begin{array}{l}\text { Initially: pitting edema; } \\
\text { Longstanding: elastic edema }\end{array}$ & Positive \\
III & Hard, enormous edema, skin changes & Positive \\
\hline
\end{tabular}

TABLE 2. Number of patients by type of edema

\begin{tabular}{|c|c|c|}
\hline \multirow{2}{*}{$\begin{array}{l}\text { Primary lymphedema } \\
139 \text { patients }\end{array}$} & \multicolumn{2}{|c|}{$\begin{array}{c}\text { Secondary lymphedema } \\
404 \text { patients }\end{array}$} \\
\hline & $\begin{array}{l}\text { Following cancer therapy } \\
227 \text { patients } \\
\text { (198 females, } 29 \text { males) }\end{array}$ & $\begin{array}{l}\text { Due to other causes } \\
177 \text { patients }\end{array}$ \\
\hline
\end{tabular}

TABLE 3. Lymphedema by localizations

776 localizations of lymphedema in $\mathbf{5 4 3}$ patients

498 localizations of lymphedema due to a non-malignant cause

483 edemas of the lower extremity 15 edemas of the upper extremity

\author{
278 lymphedemas following a malignant disease \\ 199 edemas of the lower extremity \\ 72 edemas of the upper extremity \\ 2 facial edemas \\ 2 trunk edemas \\ 1 scrotal edema \\ 1 penile edema \\ 1 breast edema
}

for melanoma can be up to $44 \%$ after therapeutic groin dissection for palpable disease, ${ }^{8}$ but the incidence following sentinel lymph node biopsy is much less. ${ }^{7,9}$

There are no available epidemiological reports of lymphedema following cancer surgery in Slovenia. A decade ago, an outpatient office specialized in lymphedema was introduced at the Department of Dermatovenerology, University Medical Center Ljubljana. As this is the only specialized center of this type in Slovenia, the number of referred patients is constantly increasing. Besides providing the best of care for these patients, one of the future aims of the center is to establish a national registry of lymphedema to provide epidemiologic data.

The clinical staging of lymphedema is shown in Table 1. Latent or subclinical (stage 0 ) lymphedema, even after surgical lymphadenectomy, may persist for months to years without any clinical evidence of lymphatic disturbance. Trigger events, e.g. insect sting, physical exertion, injuries, inflammation or warming of the limb may cause edema, which is either reversible or may, with additional lymphatic overload, proceed to the following stage. In stage $\mathrm{I}$, the edema is reversible, soft, disappearing spontaneously overnight or, with compression therapy, during the day. The skin is smooth, with small pits. Stage I may persist for several years. However, if left untreated, it sooner or later proceeds to the chronical stage II.

During the stage II, edema persists despite limb elevation. In the early stage, edema is still pitting, later the edema is non-pitting, elastic. The skin feels harder, fibrotic. This phase cannot be reversed spontaneously without therapy. The Stemmer's sign is positive - the skin on dorsal surface of the second toe cannot be pinched into a fold.

During the stage III (elephantiasis) the edema is enormous. The skin shows trophic changes (fibrosis, hyperkeratoses, papillomatosis, hyperpigmentations, lymphorea, ulcerations) and is prone to bacterial and fungal infections. The condition may 
TABLE 4. Malignancies that caused lymphedema in our patients, by the year of first referral

\begin{tabular}{|c|c|c|c|c|c|c|c|c|c|c|}
\hline \multirow[b]{2}{*}{ Cause } & \multicolumn{10}{|c|}{ Year } \\
\hline & 2002 & 2003 & 2004 & 2005 & 2006 & 2007 & 2008 & 2009 & $\begin{array}{c}2010 \\
\text { (Jan-Jun) }\end{array}$ & Total \\
\hline Breast cancer & 1 & 2 & 2 & 12 & 6 & 3 & 6 & 22 & 14 & 68 \\
\hline Uterine and cervical cancer & 6 & 9 & 13 & 8 & 9 & 7 & 3 & 11 & 1 & 67 \\
\hline Melanoma & 2 & 3 & 2 & 3 & 4 & 6 & 4 & 10 & 7 & 41 \\
\hline Sarcoma & 1 & 1 & 1 & 1 & 1 & 1 & 1 & 2 & 1 & 10 \\
\hline Colorectal cancer & 1 & 2 & 0 & 0 & 0 & 2 & 0 & 2 & 1 & 8 \\
\hline Post-radiotherapy for lymphoma & 0 & 1 & 1 & 1 & 1 & 1 & 1 & 0 & 1 & 7 \\
\hline Vulvar cancer & 0 & 0 & 1 & 2 & 0 & 1 & 1 & 1 & 0 & 6 \\
\hline Prostatic cancer & 0 & 1 & 0 & 0 & 0 & 0 & 0 & 2 & 2 & 5 \\
\hline Ovarian cancer & 1 & 0 & 0 & 1 & 0 & 0 & 2 & 0 & 0 & 4 \\
\hline Lymphadenectomy for unknown cancer & 1 & 0 & 0 & 0 & 0 & 1 & 1 & 1 & 0 & 4 \\
\hline Testicular cancer & 0 & 0 & 1 & 1 & 0 & 0 & 0 & 0 & 1 & 3 \\
\hline Bladder cancer & 0 & 0 & 1 & 0 & 0 & 0 & 0 & 1 & 0 & 2 \\
\hline Lung cancer & 0 & 0 & 0 & 0 & 1 & 0 & 0 & 0 & 0 & 1 \\
\hline Non-melanoma skin cancer & 0 & 0 & 0 & 0 & 0 & 0 & 1 & 0 & 0 & 1 \\
\hline Total & 13 & 19 & 22 & 29 & 22 & 22 & 20 & 52 & 28 & 227 \\
\hline
\end{tabular}

only partly improve with the appropriate therapy. Occasionally, development of highly malignant lymphangiosarcoma or other malignancies may ensue. ${ }^{1,10-12}$

Pain may be present during all stages. The patients also report numbness, feeling of heaviness, fatigue, paresthesias, or mobility disturbances of the affected limb. ${ }^{10-12}$

Irreversibility of the later stages of lymphedema calls for timely therapeutic intervention. The delay in seeking medical attention for lymphedema by the patient, as well as the physicians' unawareness or underestimation of the condition might lead to chronic, hard to manage problems. During followup after cancer surgery and/or radiotherapy, the physician should actively look for signs or symptoms of lymphedema, and promptly manage or refer the patient developing problems.

As in case of other side effects following cancer therapy, the therapy of lymphedema should be tailored individually. ${ }^{13}$ It should consider the patient's clinical situation, history, and any coexisting illnesses. The patient's compliance is of crucial importance. Therefore, the continuous patient education and encouragement are essential parts of the management.

Edema should be reduced as early as possible, using the compression therapy and/or manual lymph drainage. During improvement, compres- sion stockings are required to maintain the improved condition. ${ }^{11,12,14-17}$

The opinions and studies on drug therapy for lymphedema are controversial. Invasive approaches may be appropriate only in a minority of patients. Surgery may cause further damage to lymphatics, and lead to ulceration, fistulas, skin necrosis and exacerbation of edema. ${ }^{12}$

The recommended additional measures include mobilization to improve the muscle pump function. Extreme heat, cold, and trauma should be avoided. Proper skin care to prevent infections is also an important part of the management. ${ }^{11}$

\section{Patients and methods}

We performed a retrospective study of patients with lymphedema treated at the Department of Dermatovenereology, University Medical Center Ljubljana, from January 2002 to June 2010. The patients' charts were reviewed, and the following data were collected: demographic data, type of malignancy, year and type of the oncologic procedure, type, location and stage of lymphedema, time of appearance of lymphedema after the procedure, and duration of lymphedema before the first intervention. The average time of appearance of lymphedema after the procedure and the aver- 
TABLE 5. Slovenian total incidence of melanoma, breast cancer, and uterine/cervical cancer in 2002-200718, compared to the number of patients expected/referred for lymphedema after procedure for cancer. *Expected number of patients with lymphedema after therapy for the relevant condition, according to the published reports-9

\begin{tabular}{|c|c|c|c|c|c|c|}
\hline & \multicolumn{6}{|c|}{ Year } \\
\hline & 2002 & 2003 & 2004 & 2005 & 2006 & 2007 \\
\hline \multicolumn{7}{|l|}{ Melanoma } \\
\hline Total incidence & 148 & 202 & 210 & 226 & 395 & 437 \\
\hline $\begin{array}{l}\text { Expected patients with } \\
\text { lymphedema }(N)^{*}\end{array}$ & 65 & 88 & 92 & 99 & 173 & 192 \\
\hline $\begin{array}{l}\text { Referred patients with } \\
\text { lymphedema (N) }\end{array}$ & 2 & 3 & 2 & 3 & 4 & 6 \\
\hline \multicolumn{7}{|l|}{ Breast cancer } \\
\hline Total incidence & 817 & 856 & 911 & 944 & 1117 & 1153 \\
\hline $\begin{array}{l}\text { Expected patients with } \\
\text { lymphedema }(N)^{*}\end{array}$ & $106-408$ & $111-428$ & $118-455$ & $122-472$ & $145-558$ & $149-576$ \\
\hline $\begin{array}{l}\text { Referred patients with } \\
\text { lymphedema (N) }\end{array}$ & 1 & 2 & 2 & 12 & 6 & 3 \\
\hline \multicolumn{7}{|l|}{ Uterine/cervical cancer } \\
\hline Total incidence & 449 & 467 & 476 & 480 & 442 & 449 \\
\hline $\begin{array}{l}\text { Expected patients with } \\
\text { lymphedema }(N)^{*}\end{array}$ & $22-220$ & $23-228$ & $24-233$ & $24-235$ & $22-216$ & $22-220$ \\
\hline $\begin{array}{l}\text { Referred patients with } \\
\text { lymphedema }(N)\end{array}$ & 6 & 9 & 13 & 8 & 8 & 7 \\
\hline
\end{tabular}

age duration of lymphedema before the first intervention were calculated by using simple statistical methods. The expected incidence of lymphedema following melanoma, breast cancer, and uterine/ cervical cancer was calculated from the incidence reported in the Slovenian cancer registry in the years 2002-200718, and compared to the worldwide lymphedema incidence reports ${ }^{4-9}$, by using simple statistical methods.

\section{Results}

In the period of 8.5 years, 543 patients (432 females, 112 males) with lymphedema were treated. Of the 543 patients, 139 patients presented with primary and 404 with secondary lymphedema in 776 localizations. Secondary lymphedema following cancer therapy was found in 227 patients. Details are shown in Tables 2 and 3.

The average time from cancer therapy (surgery or/and radiotherapy) to the development of lymphedema was 3.4 years. In 112 patients, edema started shortly after the procedure, however, maximal time to the development of lymphedema was 31 years after the cancer therapy in one patient. The average time from the appearance of lymphedema to start of the therapy for lymphedema was 3.6 years. Only three patients received therapy for lymphedema as soon as the edema started, and maximal time from beginning of lymphedema to therapy was 28 years. The average time from cancer intervention to start of lymphedema therapy was 7 years, maximum 39 years. Only one patient received the therapy for lymphedema immediately after the procedure for cancer.

The causes of lymphedema in our oncologic patients are shown in Table 4, by the year of the first referral.

The number of patients referred for lymphedema following cancer therapy for melanoma, breast cancer, and uterine/cervical cancer from 2002 to 2007, and the comparison to the expected incidence of lymphedema is shown in Table 5.

\section{Discussion}

The reports on the worldwide incidence of lymphedema following cancer therapy in the available literature are scarce and varying considerably. Until present, there were no available epidemiological reports of lymphedema following cancer surgery/ radiotherapy in Slovenia.

The majority of patients with secondary lymphedema following cancer referred to Department of Dermatovenerology during the observed period were patients with lymphedema of the lower ex- 
tremities following uterine/cervical cancer, patients with lymphedema of the upper extremity following breast cancer, and patients following lymphedema after procedure for melanoma, accounting together for $77.5 \%$ of all patients with secondary lymphedema following cancer. The management of lymphedema in the included patient population was delayed; the patients first received therapy for lymphedema on average 3.6 years after the first signs of lymphedema and on average 7 years after the procedure for cancer.

Calculated from the reported incidence of cancer in Slovenia ${ }^{18}$ and the reported worldwide incidence of lymphedema due to cancer ${ }^{4-9}$, the expected incidence of lymphedema in Slovenia during the period 2002-2007 following melanoma, breast cancer, and uterine or cervical cancer is much higher than the actual number of patients referred to the Department of Dermatovenerology during this period. Since the Department features the only specialized center for lymphedema in Slovenia, it can be possibly concluded that many patients with lymphedema after cancer therapy remain unrecognized and untreated or undertreated.

Beside the adequate choice of the oncological treatment option ${ }^{19,20}$, the physician should actively look for signs or symptoms of lymphedema during the follow-up of patients. If lymphedema after cancer surgery and/or radiotherapy is observed, the patient developing problems should promptly be referred. Lymphedema during the early stages is a reversible or partially reversible state, whereas it is irreversible and very hard to manage if left to proceed to the late stages, causing great patient disability and predisposing them to complications, eg. infections and malignancies. The results of the present study also emphasize the need to establish a Slovenian national registry of lymphedema.

\section{References}

1. Burns T, Breathnach S, Cox N, Griffiths C, editors. Rook's Textbook of Dermatology. Oxford: Wiley-Blackwell; 2010. p. 48.1-25.

2. Rockson SG, Rivera KK. Estimating the population burden of lymphedema. Ann N Y Acad Sci 2008; 1131: 147-54

3. Clark B, Sitzia J, Harlow W. Incidence and risk of arm oedema following treatment for breast cancer: a three-year follow-up study. QJM 2005; 98: 343-8.

4. Ozaslan C, Kuru B. Lymphedema after treatment of breast cancer. Am J Surg 2004; 187: 69-72.

5. Deo SV, Ray S, Rath GK, Shukla NK, Kar M, Asthana S, et al. Prevalence and risk factors for development of lymphedema following breast cancer treatment. Indian J Cancer 2004; 41: 8-12.
6. Snijders-Keilholz A, Hellebrekers BW, Zwinderman AH, van de Vijver MJ, Trimbos JB. Adjuvant radiotherapy following radical hysterectomy for patients with early-stage cervical carcinoma (1984-1996). Radiother Oncol 1999; 51: 161-7.

7. Chatani M, Nose T, Masaki N, Inoue T. Adjuvant radiotherapy after radical hysterectomy of the cervical cancer. Prognostic factors and complications. Strahlenther Onkol 1998: 174: 504-9.

8. Allan $\mathrm{CP}$, Hayes AJ, Thomas JM. Ilioinguinal lymph node dissection for palpable metastatic melanoma to the groin. Aust NZ J Surg 2008; 78: 982-6.

9. Wrone DA, Tanabe KK, Cosimi AB, Gadd MA, Souba WW, Sober AJ Lymphedema after sentinel lymph node biopsy for cutaneous melanoma: a report of 5 cases. Arch Dermatol 2000; 136: 511-4.

10. International Society of Lymphology Executive Committee. The diagnosis and treatment of peripheral lymphedema. Lymphology 2003; 36: 84-91

11. Cohen SR, Payne DK, Tunkel RS. Lymphedema: strategies for management. Cancer 2001; 92 (4 Suppl): 980-7.

12. Rockson SG. Lymphedema. Am J Med 2001; 110: 288-95

13. Ocvirk J, Rebersek M. Management of cutaneous side effects of cetuximab therapy with vitamin K1 creme. Radiol Oncol 2008; 42: 215-24.

14. Rucigaj TP, Kosicek M, Kozak M, Grmek M. Obravnava bolnikov z limfedemom. In: Blinc A, Kozak M, Šabović M, editors. Slikovne metode v odkrivanju in zdravljenju žilnih bolezni. Ljubljana: Združenje za žilne bolezni Slovenskega zdravniškega društva; 2005. p. 168-83.

15. ISL. The diagnosis and treatment of peripheral lymphedema. Consensus document of the ISL. Lymphology 2003; 36: 84-91.

16. Földi M. Remarks concerning the consensus document of the ISL Lymphology 2004; 37: 168-73.

17. Planinšek Ručigaj $T$, Košiček $M$. Prednosti kompresijskega zdravljenja $s$ kratkoelastičnimi povoji. In: Miljković J, editor. Dermatološki dnevi. Maribor: Združenje slovenskih dermatovenerologov; 2004. p. 78-83.

18. Register raka RS [Internet]. Available at: http://www.onko-i.si/dejavnosti/ epidemiologija_in_register_raka/registri_raka/register_raka_rs/index.html. Accessed 1 September, 2010.

19. Strojnik A. Search of the shortest regimen: fractionation of a fully isoeffective combination of hyperfractionated and hypofractionated treatment. Radiol Oncol 2008; 42: 170-2.

20. Strojan P. Role of radiotherapy in melanoma management. Radiol Oncol 2010; 44: 1-12. 